\title{
A CITY THAT NEVER EXISTED: XIAO BAI'S LITERARY REMAKING OF 1931 SHANGHAI
}

\author{
Paolo MAGAGNIN \\ Department of Asian and North African Studies, Ca' Foscari University of Venice, \\ Palazzo Vendramin dei Carmini, Dorsoduro 3462, 30123, Venice, Italy \\ E-mail:paolo.magagnin@unive.it
}

Received 28 September 2016; accepted 09 January 2017

\begin{abstract}
This article provides an account of the literary recreation of the semi-colonial Shanghai of 1931, carried out by the Chinese contemporary author Xiao Bai in his 2011 novel Zujie. It also includes the features and implications of such an operation. Critically praised as a turning point in contemporary Chinese fiction about old Shanghai, the novel appears to transcend genre categories, and was welcomed as a heterogeneous "third type" crossing the boundaries between genre fiction and pure literature. Inspired by historical facts and supported by painstaking archival research, Zujie originally incorporates a variety of literary models, narrative techniques, sources, genres, themes, and perspectives. The heterogeneity at play in the novel can be essentially scrutinised at three levels. Such levels are: the debate on the genre as it emerges from a number of paratextual sources; the treatment of historical factuality and its relationship with fictional creation; the use of polyphonic devices, with reference to the portrayal of hybrid characters, deliberately disorienting narrative techniques, and a re-elaboration of imported and domestic sources and literary models that plays havoc with the very notions of foreignness and identity. Xiao Bai's original representation of 1930s Shanghai is analysed and commented upon with respect to such factors. Finally, the significance of this multi-layered literary operation and its implications for the reader are highlighted.
\end{abstract}

Keywords: Xiao Bai, Zujie, Shanghai, heterogeneity, recreation, history, postmodernist fiction.

\section{Introduction}

The late 2000s and early 2010s marked a boom in Chinese spy and crime stories set in the Republican era (1912-1949): Mai Jia's and Long Yi's latest novels, which are set against the background of the period spanning from the 1920s through the 1940s - as well as their adaptations into films and/or TV series - are but a few examples of a genre that is still thriving to this day (Lu Ye 2013: 12). Among these works, Zujie (The Concession) holds a special place. Immediately after its publication in March 2011, the novel was critically praised in China as a distinctive achievement in contemporary fiction set in the city of Shanghai for its complex narrative technique, its original treatment of history, and its depiction of multifaceted characters. The author, Xiao Bai (pen name of Zhang Haibo, b. 1968), is a Shanghai-born writer, journalist, and essayist who had already earned a reputation thanks to the essay collection Haose de Hamulaite (Xiao Bai 2009) and the novel Judian (Xiao Bai 2010). He also authored the collection of literary essays titled Biaoyan yu toukui (Performance and voyeurism, 2012).

After narrating the Shanghai of the early 1990s in Judian, Xiao Bai sets his following novel in the same city but sixty years earlier. This period in history is when the "Paris of the Orient" epitomised the semi-colonial regime to which China had sunk after its clash with Western powers since the mid-19 $9^{\text {th }}$ century. In 1931, when the story recounted in Zujie takes place, the Shanghai urban area was subdivided into three sections: a Chinese city under the jurisdiction of the Nanjing-based Nationalist government, an International Settlement under British-American rule, and a French Concession directly administered by Paris. In the opening pages of the novel, a top official of the Nationalist government named Cao Zhenwu is shot dead only minutes after setting foot on the wharfs of the French Concession, on May 19, 1931. The FrancoChinese photographer Xiao Xue and his lover Therese Irxmayer are also aboard the boat by which Cao and 
his wife Leng Xiaoman have reached Shanghai. It is Therese, a mysterious femme fatale, who initially attracts the attention of the French police commanded by Lieutenant Sarly. However, the investigation quickly focuses on the Organisation, an allegedly revolutionary group led by its enigmatic leader Gu Fuguang. Xiao Xue is also involved: recruited by Sarly as an undercover detective to keep an eye on Therese's activities, he is soon overwhelmed by the task and begins a thorny ménage à trois involving Leng Xiaoman. The latter has meanwhile joined Gu's Organisation, eager to avenge the execution of her first husband by Cao Zhenwu. To complicate things further, a special investigation team at the orders of the Nationalist government is also tracking the Organisation. Gu Fuguang's real purposes are soon exposed: far from upholding noble revolutionary ideals, he is revealed to be a nihilist planning to destroy the decrepit power structures that control Shanghai - not only the Nanjing government and the foreign colonisers, but also the old triads and especially the Green Gang - by spreading terror and storming the Shanghai Race Club, making sure his every move is duly captured on film. The attempted assault fails and a few days later Gu himself is killed by Xiao Xue in a shooting that also claims Leng Xiaoman's life. The narration closes in early February of 1932, with the menacing rise of Japan and the shadow of the impending war looming over Shanghai. Western expatriates start to flee and the golden era of the Paris of the Orient quickly rushes towards its end.

Inspired by real events and characters, and supported by painstaking archival research, the story recreates old Shanghai by amalgamating a variety of both native and foreign literary models and sources, narrative techniques and themes. In fact, Zujie is a complex, fragmented, and multi-layered text that redefines models and genres, revisiting the recent past and addressing a set of issues that are still controversial in today's China. The book gained special attention outside China, testifying to its appeal to an international audience: an Italian translation was published (Xiao Bai 2013), followed by an English (Xiao Bai 2015) and a French translation (Xiao Bai 2016).

In this paper I will provide an account of the factors of heterogeneity observable in Zujie at three levels, namely: 1) the debate on the genre, as it emerges from paratextual sources; 2 ) the treatment of historical truth and its problematic relationship with fiction; 3 ) the use of polyphonic devices, with reference to the depiction of hybrid characters, deliberately disorienting narrative techniques, and a re-elaboration of native and non-native voices, sources and literary models that challenges the very notions of foreignness and identity. Finally, the relevance of this heterogeneity in the literary remaking of the history of Shanghai and its implications for the reader will be scrutinised.

\section{The genre debate: a "third type" in the Chinese literary landscape?}

The complexity of Zujie is reflected in the many ways in which publishers, critics, writers, scholars, reviewers, and other agents have labelled the novel. As a matter of fact, its appearance seems to have sparked a lively debate addressing, to a more or less explicit degree, the very boundaries of genre fiction (leixing xiaoshuo) and pure literature (chun wenxue).

If the bellyband prepared by the publisher presents the book as "the first Chinese work of fiction based on purely historical details", the synopsis in the publishing house's website offers a more articulate description. The novel is presented first as a "spy novel" (diezhan xiaoshuo and anzhan xiaoshuo), then as a "political noir novel", (zhengzhi anhei xiaoshuo), then again as an "intellectual novel" (zhishifenzi xiaoshuo). ${ }^{1}$ Labels set aside, the publisher stresses how the nature and psychology of its characters sets Zujie apart from most spy stories: by exploiting the "shell" provided by popular literature, the novel transcends genre boundaries, revealing a deeper emphasis on the investigation of human nature than is usually the case in crime fiction (Renmin Wenxue Chubanshe 2011).

The misleading association of Zujie with the spy story genre is frequently evoked, and subsequently refuted, in a number of other commentaries. According to the contemporary writer Qiu Huadong, at first the novel may actually be reminiscent of Mai Jia's novels. However, Qiu states, the two writers have a completely different vision of both the world and literature; moreover, "the way in which old Shanghai is imagined in Zujie transcends every other novel depicting old Shanghai" (Qiu Huadong 2011). Zujie's originality is also mentioned by Huang Yuning, who stresses its radical difference from the previous "spy literature" (diezhan wenxue) (Huang Yuning 2011). In a dialogue with the author, the writer Sun Ganlu also remarks that Zujie, unlike most contemporary spy novels - whose plots habitually involve the accomplishing of a great enterprise, of an ideal - depicts events that are completely beyond control, while the individuals involved in such events struggle to influence the course of things: in this respect, Sun believes, "this novel surpasses other genre fiction works” (Xiao Bai 2012: 345).

1 Unless otherwise stated, all English translation are my own. 
The distance that sets Zujie apart from crime fiction, as the latter is commonly understood, is reflected in the references to literary models that are not - or at least not exclusively - associated with the genre. In his preface to the novel, the influential writer and literary critic Li Jingze (2011) suggests that the Shanghai depicted in Zujie is certainly bound to be compared to the urban space described by other Chinese authors whose literary creation is intimately connected with the city, notably Eileen Chang (Zhang Ailing) and Wang Anyi. However, praising the author's ingenious portrayal of characters and sophisticated narrative skills, $\mathrm{Li}$ affirms that Xiao Bai "recreates this city entirely". Interestingly enough, the critic also mentions Graham Greene as a major influence, seeing in Xiao Bai "the only Chinese author with a British demeanour" and comparing his dynamic writing, attention for details, and unpredictable narration to Greene's (Li Jingze 2011). Pesaro (2013) sees in Zujie essentially the result of a refashioned native literary tradition. Within the framework of a Western-style noir novel, she argues, Xiao Bai recreates the urban literary models of the 1930s and 1940s: Eileen Chang above all, but also Ding Ling, Mao Dun, the writers of the New Sensationalist School (Xin ganjue pai), and the "revolution plus love" formula found in the leftist literature of the 1930s (Wang 2004: 9). Conversely, Yang Kui (2011) insists on Xiao Bai's debt towards Anglo-American literature, likening the novel to non-Chinese masterpieces such as Eco's Foucault's Pendulum, Lodge's Small World, and Nabokov's Pale Fire. "The impression of reading a foreign novel”, and precisely a book written in imitation of Borges' language, is similarly evoked by Jiang Yan (2011), while Feng Tao states that Xiao Bai "is writing in the tradition of Honoré de Balzac" (HarperCollins Publishers 2015).

On a less formalistic note, Zhu Jisong does not consider the novel a Western-style best-seller, nor a mere archival document, but rather "an expression of respect and consolation by a 'philosopher in the attic' towards his native city, towards its wrinkles and scars, an act of nonviolent resistance to claim the right to a poetic existence" (Zhu Jisong 2011:97). The merit of the book, according to Li Weizhang (2011), lies ultimately in its ability to cross the boundaries between genre fiction and pure literature, establishing a "third type" that proves it is possible to combine the stimulating pace and narrative techniques of the former and the stylistic refinement of the latter. Li's claim is echoed by Pesaro: "genre fiction acquires, thanks to Xiao Bai, a value and a polyphony so far unexplored in today's China" (Pesaro 2013: 7).

\section{Between accuracy and fabrication: the puzzle that is history}

In China, from the remote past to the beginning of the $20^{\text {th }}$ century, historiography had always occupied one of the most prominent positions in the hierarchy of discursive genres. Fiction, on the other hand, had constantly appeared in a state of inferiority vis-à-vis its nobler counterpart, despite its attempts to prove capable of complementing official histories (Zhao 2006). This relationship was subverted in the aftermath of the May Fourth Movement ${ }^{2}$ (Wusi yundong), when fiction became a genre in its own right and was granted a higher cultural and pedagogical role than historiography. In the 1920s, Chinese fiction typically revolved around psychological introspection and self-expression: in the late 1930s, however, the historical and social novel came into prominence, beginning to draw on history in its representation of the Zeitgeist. In the post-Mao era, when the strongly ideological concept of artistic creation began to lose force, a debate on the recent past was initiated: however, the "fiction of the new era" (xin shiqi xiaoshuo) did not manage to develop into a real form of historiographic literature. The 1990s saw the emergence of the "new historical novel" (xin lishi xiaoshuo), whereby several avant-garde writers experimented with the introduction of personal accounts in a historical framework, putting into practice innovative narrative techniques, and adopting a new approach to history that sometimes took the form of an overt subversion of official historiography. In more recent times, other authors seem to have set aside avant-gardist and postmodernist techniques, going back to the tradition of the historical novel (Pesaro 2005).

The literary reconstruction of historical reality is one of Zujie's most conspicuous traits. It is evident in the meticulous accounts of the urban landscape of pre1949 Shanghai, where native and foreign languages are constantly intertwined in the names of streets, businesses, hotels, clubs, public bodies and so on:

Behind [Gu], a narrow street called Rue de la Porte de l'Est ran south along the Quai de France, two blocks from Rue Takoo and parallel to it. On the side that intersected

\footnotetext{
2 A nationalistic, anti-imperialistic and anti-traditional protest movement that broke out against the resolution of the 1919 Paris Peace Conference, whereby the former German territories of Shandong were granted to Japan instead of being returned to China. It later developed into a cultural movement, appropriating many of the claims previously expressed by the New Culture Movement (Xin wenhua yundong), advocating the rejection of traditional Confucian values and calling for Western-style modernisation. In the literary field, the authors associated with the Movement notably promoted the use of vernacular language and the reception of foreign genres and theories.
} 
with the Quai de France, there was an iron gate with a police guard post. Farther south, where the French Concession ended and Chinese territory began, the road was called Waima Road, and the building on the intersection where the Quai de France became Waima Road was the headquarters of the Shanghai Special Marine Police Branch. [...] [Gu] himself was standing at the spot with the best view, and he had a clear view of the entrance to Kin Lee Yuen Wharf. The Peugeot was parked on the other end of Rue Takoo, near Rue du Whampoo (Xiao Bai 2015: 10).

Sometimes, as is the case in the excerpt above, the narration of fast-paced actions and complex topographies can prove bewildering. For this reason, such passages are accompanied and clarified by a number of maps, conveniently reproduced in the English edition.

Moreover, the Chinese original shows a large use of footnotes specifying the international counterpart to proper names that appear in Chinese transcription in the body of the text, or vice versa: this sort of philological preoccupation on the part of the author sometimes gives the impression of reading a piece of scholarly research rather than a work of fiction. The "accuracy of the archaeologist" (Li Jingze 2011: ii) also emerges in the intertextual references with which the narration is interspersed. These come largely from the archival research conducted by Xiao Bai on coeval documents. Such references take different forms and degrees, from simple allusions to overt quotations: cablegrams, police reports, governmental decrees, excerpts of diplomatic correspondence, catalogues of local celebrities, revolutionary pamphlets, newspaper and magazine cuttings, film dialogues and so on. Intertextual references are sometimes reproduced verbatim and in their original (foreign) language, thus creating a powerfully distantiating effect on the reader - even more so on the Chinese one, because of the graphic difference between Latin alphabet and Chinese script.

A peculiar form of historical reconstruction involves the ekphrastic descriptions of photographs, billboards, film scenes and other visual documents, many of which - again -were gathered by the author as a source of inspiration. The following passage, for instance, describes the photographs sent home by Xiao Xue's father while at the front during WWI:

In one of them, a Zulu regiment was performing a religious ceremony. [...] Wearing nothing but a piece of cloth around their waists, they waved their sticks, dancing with rapt expressions. [Xue]'s favorite one was of his father smoking a pipe in the trenches in summertime, his chin covered with stubble, shirtsleeves torn short at the shoulders. In another photo, a man posed stark naked at the entrance to the shower cubicles while his uniform hung on the wall. It was his father, grinning at the camera with one hand covering his pubic hair. [...] There was a line in French on the back: Poux - Je n'ai pas de poux! Lice - I have no lice! [...].

That winter, his father posed for a photo next to a row of corpses. He wore his jacket and a water canteen slung over his shoulder. There were so many corpses that it looked like a slaughterhouse. Some were laid out side by side, while others were piled on trucks like garbage. In fact, the injured looked even more horrific than the dead. One man was wrapped from head to toe in bandages, excepting three holes for his eyes and nose (Xiao Bai 2015: 23-24).

A sense of historical accuracy is conveyed by the constant detailed references to events, urban fads and phenomena, customs and habits of both the Chinese and the foreign citizens of Shanghai. The painstaking attention to detail is also reflected in a number of indications, descriptions, and explanations: the date and time at the beginning of each chapter - as in "May 19, year 20 of the Republic, 2:24 A.M." (Xiao Bai 2015: 1) the exact coordinates of the berthing point of a steamship, the morphology of the sea bottom off the Yangtze river delta, the etymology of the name of a specific strip of land in Pudong, the brands of clothes, cigarettes, and other articles of daily use and so on.

Finally, the introduction of actual historical characters who move alongside fictional ones is equally vital to the building of a sense of factual reliability. The most remarkable example of this operation is the character of Roland Sarly, Lieutenant of the Garde Municipale, who was indeed a complex - and in many respects ambiguous - protagonist of the late stages of French colonial rule in Shanghai (Bergère 1998), and who also plays a key role in the development of the plot.

Nevertheless, in Zujie, history resurfaces only occasionally in this sequence of details and pieces of a "cognitive puzzle" (zhishi pintuban) (Xiao Bai 2012: 338), remaining fragmentary and chaotic despite its apparent completeness and accuracy. The relationship that these details entertain with history is a feeble and partial one: far from depicting historical reality in its entireness, they become at best a tool allowing the reader to "peek at" (kuishi) it from the outside (Xiao Bai 2012: 337). The great events that are mentioned in the story do 
not delineate a historical background against which the narration develops, but rather help to conjure the disturbing atmosphere that permeates the entire novel. In fact, throughout the narration, the tragedy of the impending war is constantly hinted at and anticipated by a succession of ominous signs that are only apparently unrelated. Only in the epilogue and in the afterword by the author do the pieces of the puzzle seem to fall into place: finally, all those seemingly isolated events appear to be the stages of a tragic collapse, where the decline of colonial powers in Asia, the rise of Japanese imperialism, and the seeds of the social and political contrasts that shook China throughout the $20^{\text {th }}$ century are intimately interlaced.

Therefore, if on the one hand the painstaking attention to details and documentary evidence seems to draw the reader closer to the historical truth, luring them by the illusion of realism, on the other hand it keeps them at a distance, precisely because the attempted portrayal of truth relies heavily on multiple sources, second-hand impressions, and bits of information. In the final analysis, when confronted with such a "cognitive puzzle", the reader may sink into the same dilemma in which Lieutenant Sarly finds himself when he tries to find a logic in his investigation:

Maybe the truth was a heap of documents, newspaper cuttings, and interrogation notes. Maybe it was what people whispered to each other in the alleyways, what the plainclothes investigators wrote in their daily reports. Maybe the truth existed only in their files (Xiao Bai 2015: 86).

Where facts become hazy, the legend begins: the same legendary aura that infuses the Concession, compared to "a floating city, rootless, without a past and with no guarantee of a future, [...] like a huge vat of dye that tinted all its characters with the quality of timelessness, which turned them into legends" (Xiao Bai 2015: 58).

The illusion of realism is further undermined by the occasional riddles devised by the author, who conceals fictional and humorous elements behind the ostensible exactness of documentary evidence. This is the case, for instance, of the serial number of a police file mentioned in the appendices, "U731-2727-2922-7620", a detail that is implicitly presented as an incontrovertible guarantee of historical accuracy (Xiao Bai 2015: 349). However, if we break up the serial number, we obtain the sequences 73127,27292 , and 27620: in the character encoding system known as "four-corner number dictionary" (sijiao haoma zidian), these codes correspond to the three Chinese characters composing the sentence pian ni de, "I tricked you" (Huang Yuning 2011).
Because of these fragmentary accounts and the coexistence of plural realities, an unambiguous reconstruction of history becomes impossible. Far from being a traditional historical novel, then, Zujie is much closer to a form of historiographic metafiction, where only multiple truths exist and the dichotomy between truth and falsity proves unproductive in critical terms. History and fiction, as equally authoritative narrative practices, are demarcated by boundaries that the novel first defines and then puts to the test, challenging at the same time the alleged authenticity of historiographic representations and the equally alleged inauthenticity of their copies (Hutcheon 2000: 834).

\section{Levels of heterogeneity}

\section{Hybrid identities, multiple gazes}

The impossibility of a clear-cut reconstruction of truth, as well as the polyphony at play in the novel, are also reflected in the hybrid nature of its characters. Their identity is often uncertain, their ethnicity sometimes hard to define, and their background almost regularly resulting from a mixture of different experiences. The protagonist Xue Weishi - usually referred to as Xiao Xue, "Young Xue", but also by his Europeanised name "Weiss Hsueh" - is a half-blood playboy born of a French father and a Cantonese mother. His lover Therese Irxmayer - or "Lady Holly", as the Chinese call her - is a White Russian Jew claiming to be German who, like thousands of fellow countrymen, fled Russia in the aftermath of the 1917 Revolution to find shelter in Shanghai. Therese's secretary Chen Zimi - or Zung Ts-mih, in the Cantonese romanisation - is a Hong Kong-born comprador identified first as a "British subject of "mixed blood" and then as "Siamese" in police reports (Xiao Bai 2015: 28). Before becoming the elusive leader of the Organisation, Gu Fuguang also known as Gu San or Gu Tinglong - was a worker and an activist in a Shanghai factory, a prisoner in an Azerbaijani internment camp, a recruit in Russia and a guerrilla fighter in the British colonies of Southeast Asia. According to Li Jingze, these are "characters that were never seen before, not only because of their peculiar identities, experiences, and fates, but also because they possess a distinctive originality in terms of characterisation as the latter can be observed in Chinese fiction" (Li Jingze 2011: iii).

The characters' ambiguity and their complexity appear at another level, that of double-cross and theatricality. The former is a fundamental element in the unfolding of the plot of Zujie. It is notably recognisable in the intricate web of two-timing love affairs, interests, and crossed loyalties in which Xiao Xue finds himself 
entrapped. Therese's double life, as a jeweller and a weapon smuggler, and Leng Xiaoman's dilemma - she is torn between her desire for vengeance, her love for Xiao Xue, and her revolutionary ideals - are but a few examples of the ubiquity of double-cross. Theatricality is also systematically employed as a narrative device: performance (biaoyan) even becomes a major semantic field in the novel, whereby the characters - more or less knowingly - act with a constant eye to the persuasiveness and to the effect of their actions on the "audience". This is clearly observable in the accounts of the love affair between Xiao Xue and Leng Xiaoman, as well as in the Debordesque observations on the power of cinema in which Gu Fuguang engages (Magagnin 2014: 248-250).

The importance of cinema in the novel is not confined to Gu's reflections. Not only are cinematic techniques employed in the description of action scenes; the narrative structure itself seems to draw inspiration from film grammar (Jiang Yan 2011). Each chapter is in turn presented from the viewpoint of a different character, as in a subjective shot delimiting a specific portion of space and time; moreover, the same scene is often narrated several times and from different angles. Once again, a multiplicity of gazes is at play which only offers a fragmentary sequence of frames, thus challenging the unequivocal reconstruction of reality (Magagnin 2014: 250-251).

\section{Foreignising the familiar, embracing the foreign}

The novelty of the characters found in Zujie also resides in their unique mind-set and metacultural reflections. Just like many Chinese characters seem to have adopted a foreign way of thinking, some of the settlers are ready to immerse themselves in the local culture in order to better grasp it. For instance, Lieutenant Sarly - a passionate reader of Chinese newspapers proves knowledgeable in the principles of intercultural communication when recruiting Xiao Xue in order to investigate the murkiest mysteries of the Concession. This is based on the belief that his protégé's "Chinese face would give him access to what Sarly thought of as Shanghai street savvy and that his French heart would prompt him to report it to Sarly" (Xiao Bai 2015: 134). Together with the intertextual references mentioned above - which often give voice to foreign perspectives on the Concessions and in some cases contain views expressed either by the Chinese residents about Westerners, or by nationals of a given country about nationals of other countries - these metacultural remarks offer a variety of outlooks that is seldom found in Chinese literature. By incorporating into the text
Western-filtered narratives of Shanghai, which can be seen as the result of a "back-translation" (huiyi) (Xiao Bai 2012: 350), the author urges the readers to confront themselves with a plurality of viewpoints, and to re-examine not only the tragic experience of foreign imperialism, but also their own national and cultural identity.

An interesting effect of overlapping perceptions is also triggered by the coexistence of native and non-native literary models depicting the Shanghai urban space. As often mentioned in paratextual sources, echoes of Chinese urban literature of the Republican era and later fiction about old Shanghai can be perceived in the novel. In this respect, Xiao Bai makes broad use of a peculiar form of intertextuality, namely interdiscursivity, which focuses on the relation between texts at the level of semantic and syntactic features shared by a specific type of discourse or genre, hence revealing the traits of a voluntary inheritance (Segre 1985: 86). The comparison between the following excerpts, drawn from Zujie and Eileen Chang's 1950 novella "Lust, Caution" (Se、jie) respectively, is but an example of such operation:

She drove north along Rue Paul Beau. The rusty gates to the longtangs along the road had been left ajar, and the scent of canola oil wafted out. Therese rolled up the windows. She soon turned onto a wider road. The light reflected illusory movie posters onto the windows of the car: the RKO Pictures musical Tanned Legs and His Glorious Night with John Gilbert in a mustache. In a lit shop window, a polar bear held a sign in his mouth that said SIBERIAN FUR.

Then the road grew narrower and the dark shadows of buildings loomed ahead. At night, the walls of flint and marble looked as though they had been hewn directly from the hillside (Xiao Bai 2015: 52).

The car made a U-turn at the next crossroads, and then another a little farther on to get them back to the P'ing-an, the only respectable second-run cinema in the city. The building's dull red facade curved inward, like a sickle blade set upon the street corner. Opposite was Commander K'ai's Café again, with the Siberian Leather Goods Store and the Green House Ladies' Clothing Emporium next, each fronted by two large display windows filled with glamorously dressed mannequins bent into all manner of poses beneath neon signs. The next-door establishment was smaller and far more 
nondescript. Although the sign over the door said JEWELER'S, its single display window was practically empty (Chang 2007: 30).

The two passages show a marked similarity in several respects: this similarity is particularly evident in the action depicted (a femme fatale's car ride on the avenues of the French Concession) and in the symbols of modernity that are conjured (neon signs, billboards, cafés and shops, and especially the famous Siberian Fur Store in Bubbling Well Road). However, attention must also be paid to a number of stylistic features (e.g. the insertion, in the Chinese original, of Latin letters that are capitalised in both English translations) and to modernist-style figurative language (the description of ominous-looking buildings). In fact, the glamorous representation of the "Shanghai modern" (Lee 1999) is commonly found in modern Western-influenced urban Chinese literature - exemplified by Chang's fiction since the 1920s through the late 1940s and is an almost ubiquitous trope in later representations of the city. In this and other instances, such literary echoes can be easily recognised by the educated Chinese reader of Zujie, who has also access to a plethora of cinematic interpretations of the same city - the best known being precisely, in this case, Ang Lee's 2007 film Lust, Caution, already mentioned as a benchmark by $\mathrm{Li}$ Jingze (2011: iii).

However, in spite of the exotic setting, the description of the city may also prove familiar to an international readership, as "this novel perfectly fits the image of the East that Westerners have: to them, the Shanghai described in Zujie is both familiar and close" (Shi Jianfeng 2013: B01). In fact, the non-Chinese reader is very likely to discover that Xiao Bai's Shanghai is informed by aesthetics that are strikingly similar to those employed - to name but an example - in Lee's Lust, Caution, the film that made the "Shanghai modern" imagery accessible to an international audience. In addition to this, such recognisability is also analysable in terms of genre, with reference to the Western-derived "shell" provided by spy fiction. The exportability of the genre, with which Zujie has been promptly - although problematically - identified outside China, seems to have been a precondition for its purchase by Western publishers, led by the Italian Sellerio. In fact, the operation has been seen as "part of a trend, signaling increased interest in Chinese literature among Western publications and readers" (Chung Dawson 2013): despite having "sold only moderately well in China, [Zujie] has the elements that appeal to Western readers", mainly because "it is suspense, a genre that isn't very popular in China but sells solidly in the West" (Yao 2013).
In the final analysis, the intersection of native and foreign voices, both in terms of metacultural reflections and artistic stylemes, creates - typically in the Chinese readership but also, in different forms and to a different extent, in the readers of the translated text - a short-circuit that plays havoc with the very boundaries between "native" and "foreign".

\section{Conclusions}

The originality of Xiao Bai's literary operation lies in his ability to gather and reinvent a variety of heterogeneous elements that allow the author to fashion an entirely new city, one that surpasses all its other representations: it is a Shanghai that has never been seen before, "possibly a Shanghai that never existed" (Jiang Yan 2011: C05).

In terms of literary genre, approaching Zujie as a work of crime fiction may prove deceptive. The novel is the result of a combination of genres, models and narrative techniques: spy story à la Ellroy, but also political thriller, historical novel, Bildungsroman, revolutionary romance. It reveals the coexistence of Chinese and Western models, combined with an exploration of human nature and history that is rarely found in popular literature. Xiao Bai revitalises these variegated elements, pouring them into the container offered by crime fiction and thus "expanding the narrative space of Shanghai urban literature" (Li Weizhang 2011). From this perspective, Zujie can at best fit into the definition of postmodern crime fiction, "with its tonal complexity and its rejection of ancient traditions of certain knowledge, assured identity and detective-centred moral authority" (Knight 2004: 197).

Furthermore, when it embraces a postmodernist approach, crime fiction can, "by being less determinate and simplistic than usual in its processes and outcomes, be a means of questioning certainties about the self, the mind and indeed the ambient world" (Knight 2004: 195). When it comes to the treatment of historical truth, the very notions of identity and otherness, of familiar and unfamiliar are put to the test: in De Groot's words, the historical novel "explores the dissonance and displacement between then and now, making the past recognisable but simultaneously authentically unfamiliar" (De Groot 2010: 4). If we assume that Zujie is indeed (at least partly) a historical novel, it is a deeply subversive one, because it is permeated with a dialectical discourse that aims at disrupting (and sometimes reconstructing deliberately) difference and identity, transformation and continuity, ultimately eliciting an active response from the reader. Through the constant overlapping of perspectives and gazes, of history and narration, of truth and fiction, Zujie triggers a mixed 
range of impressions in the readers, urging them to adopt a sceptical outlook on reality. In fact, as postmodern fiction suggests, "to re-write or to re-present the past in fiction and in history is, in both cases, to open it up to the present, to prevent it from being conclusive and teleological" (Hutcheon 2000: 834).

By rewriting this specific stage of Chinese history in the key of uncertainty and possibility, and dissecting it by a polyphonic approach, Zujie extends such scepticism to the present. Through its bewildering representation of 1930s Shanghai, Xiao Bai's novel raises, from a historical perspective, a number of issues that are still painfully felt in today's China - the scars of colonialism, the definition of national identity, the relationship with the West, the ongoing struggle between socialist values and the capitalist drive, the rampant political corruption, the power of mass media and so on - casting a light on a present proving less monolithic and more problematic than that portrayed in the discourse of officialdom.

\section{Acknowledgements}

The author wishes to thank Ms. Martina Codeluppi and the two anonymous reviewers for providing valuable critical comments on an earlier version of the manuscript.

\section{References}

Bergère, M.-C. 1998. The purge in Shanghai, 1945-46: The Sarly affair and the end of the French concession, in W. Yeh (Ed.). Wartime Shanghai. London and New York: Routledge, 161-180.

Chang, E. 2007. Lust, caution: the story. New York: Anchor Books.

Chung Dawson, K. 2013. Culture gap proves a challenge for booksellers [online], [cited 14 February 2016]. China Daily USA. July 22, 2013. Available from Internet: http://usa.chinadaily.com.cn/opinion/2013-07/22/content_16811604.htm

De Groot, J. 2010. The Historical Novel. London and New York: Routledge.

HarperCollins Publishers. 2015. French Concession. A novel [online], [cited 14 February 2016]. HarperCollins Publishers. Available from Internet: http://www.harpercollins. com/9780062313454/french-concession/

Huang Yuning. 2011. Nining de guanxi [Muddy liaisons] [online], [cited 14 February 2016]. Douban. April 25, 2011. Available from Internet: http://book.douban.com/review/4921899/

Hutcheon, L. 2000. Historiographic metafiction, in M. McKeon (Ed.). Theory of the novel. A historical approach. Baltimore, London: Johns Hopkins University Press, 830-850.

Jiang Yan. 2011. Xiao Bai: “Zujie” shi cong wei cunzai guo de Shanghai [Xiao Bai: Zujie is a Shanghai that never existed]. Xin Jing bao - Shuping zhoukan, May 14, 2011, C05.

Knight, S. 2004. Crime fiction, 1800-2000. Detection, death, diversity. New York: Palgrave Macmillan.
Lee, L. O. 1999. Shanghai modern. The flowering of a new urban culture in China, 1930-1945. Cambridge, MA: Harvard University Press.

Li Jingze. 2011. Xu - Sheyingshi、 lianjinshushi ji chongjian yi ge Shanghai [Preface: photographers, alchemists, and the rebuilding of Shanghai], in Xiao Bai. Zujie. Beijing: Renmin Wenxue Chubanshe, i-vi.

Li Weizhang. 2011. Zujie biaoqian, Xiao Bai zhizao [Brand: Concession, manufacturer: Xiao Bai]. Wenxue bao, June 23, 2011, 8 .

Lu Ye. 2013. Diezhan xiaoshuo yu dangdai Zhongguo de qinggan jiegou: cong Mai Jia, Long Yi dao Xiao Bai [The spy novel and the feeling structures of contemporary China: from Mai Jia and Long Yi to Xiao Bai], Xiandai Zhongwen xuekan 3: 12-21, 59.

Magagnin, P. 2014. Doppio gioco e finzione nella Shanghai degli anni '30. Zujie e il noir storico cinese [Double-cross and fiction in 1930s Shanghai. Zujie and the Chinese historical noir novel], in A. Calanchi (Ed.). Arcobaleno noir. Genesi, diaspora e nuove cittadinanze del noir fra cinema e letteratura. Giulianova: Galaad Edizioni, 231-255.

Pesaro, N. 2005. Storiografia d'amore. Osservazioni sul "ritorno alla Storia" nel romanzo di Ye Zhaoyan Yijiusanqi nian de aiqing [A love historiography. Some observations on the "return to History" in Ye Zhaoyan's novel Yijiusanqi nian de aiqing], in M. Scarpari, T. Lippiello (Eds.). Caro Maestro... Scritti in onore di Lionello Lanciotti per l'ottantesimo compleanno. Venice: Cafoscarina, 897-913.

Pesaro, N. 2013. Estetica del noir su sfondo cinese [The aesthetics of noir novel against a Chinese background]. Il Manifesto - Alias, 7 April, 2013, 7.

Qiu Huadong. 2011. Xiao Bai de “Zujie” [Xiao Bai’s Zujie] [online], [cited 14 February 2016]. Qiu Huadong de blog. March 14, 2011. Available from Internet: http://blog.sina.com.cn/s/ blog_53a1468b0100q7jq.html/

Renmin Wenxue Chubanshe. 2011. Xinrui zuojia chongxie modu Shanghai wujiandao, zhishi pintu tuigao diezhan xiaoshuo xin redian [A ground-breaking writer rewrites the world of undercover cops in the mysterious metropolis of Shanghai, a cognitive puzzle raises the interest in spy novels] [online], [cited 13 October 2014]. Available from Internet: http://www.rw-cn.com/templet/renwen/newsInfo. jsp?id=131282/

Segre, C. 1985. Avviamento all'analisi del testo letterario [An introduction to the analysis of the literary text]. Turin: Einaudi.

Shi Jianfeng. 2013. "Zujie" de chenggong yu Yazhou banquan shuchu ruoshi [Zujie's success and the weaknesses of copyright exporting in Asia]. Dongfang zaobao, June 28, 2013, B01.

Wang, D. D. 2004. The monster that is history. History, violence, and fictional writing in twentieth-century China. Berkeley and Los Angeles: University of California Press.

https://doi.org/10.1525/california/9780520231405.001.0001

Xiao Bai. 2009. Haose de Hamulaite [Lustful Hamlet]. Beijing: Renmin Wenxue Chubanshe.

Xiao Bai. 2010. Judian [Game point]. Shanghai: Shanghai Wenyi Chubanshe.

Xiao Bai. 2011. Zujie [The Concession]. Beijing: Renmin Wenxue Chubanshe.

Xiao Bai. 2012. Zujie na xie shir - Yu Sun Ganlu duitan [About the Concession: a dialogue with Sun Ganlu], in Biaoyan yu 
toukui [Performance and voyeurism]. Shanghai: Shanghai Yiwen Chubanshe, 334-351.

Xiao Bai. 2013. Intrigo a Shanghai [An intrigue in Shanghai]. Palermo: Sellerio Editore.

Xiao Bai. 2015. French Concession: A Novel. New York: HarperCollins.

Xiao Bai. 2016. La Concession française [The French Concession]. Arles: Philippe Picquier.

Yang Kui. 2011. Lao Shanghai shi zhi laohu yao chi ren de [Old Shanghai is a man-eating tiger] [online], [cited 14 February 2016]. Douban, April 1, 2011. Available from Internet: http://book.douban.com/review/4887415/

Yao, M. 2013. Old Shanghai thriller lures western publisher [online], [cited 14 February 2016]. Shanghai Daily, July 20, 2013. Available from Internet: http://www.shanghaidaily. com/Feature/art-and-culture/Old-Shanghai-thriller-luresWestern-publisher/shdaily.shtml/

Zhao, H. Y. H. 2006. Historiography and Fiction in Chinese culture, in F. Moretti (Ed.). The novel, Volume 1: history, geography and culture. Princeton: Princeton University Press, 69-93.
Zhu Jisong. 2011. Jihuo jushi de huxi - Xiao Bai “Zujie” duhougan [The breath of living rocks: impressions after reading Zujie], Shucheng 8: 62-67.

\section{PAOLO MAGAGNIN}

is Assistant Professor of Chinese at the Ca' Foscari University of Venice and a corresponding member of the IrAsia research group at CNRS/Aix-Marseille Université. His fields of research include Chinese modern and contemporary literature (fiction of the Republican era, genre fiction), didactics of Chinese literature and culture, translation studies (translation criticism, ideology in translation, translation of figurative language), and contemporary Chinese political discourse. He is also a translator of contemporary Chinese literature, including works by Zhu Wen, Xiao Bai, Xu Zechen, Cao Wenxuan, Chen He, and $\mathrm{A}$ Yi. 